\title{
Kurak ve Farklı Eğim Koşullarına Sahip Bir Arazi Toplulaştırma Sahasının Çölleşme Potansiyelinin Klasik İstatistiksel Yöntemlerle Araştırılması
}

\author{
Murat ALTUNSU ${ }^{1}$, İfan OĞUZ ${ }^{1 *}$, Rasim KOÇYİĞİT ${ }^{1}$ \\ ${ }^{1}$ Tokat Gaziosmanpaşa Üniversitesi, Ziraat Fakültesi, Toprak Bilimi ve Bitki Besleme, 60250, Tokat
}

Öz

Klasik istatistiksel yaklaşımlar, topraklardaki heterojenliği tanımlayarak farklı toprakların çölleşme eğilimlerini karşılaştırmaya imkan verebilir. Bu çalışmada mera ve tarım arazilerine sahip, kurak iklim koşullarında yer alan bir arazi toplulaştırma sahasının çölleşme eğilimi değişim katsayıları dikkate alınarak değerlendirilmiştir. Çalışmada, dört farklı eğimde (\%0-2, \%3-6, \%7-12, > \%12), on altı adet toprak değişkeni için çölleşme eğilimini tanımlamak üzere değişim katsayısı değerleri belirlenmiştir. Bu amaçla, Aksaray-Ortaköy ilçesi arazi toplulaştırma projesi sahasından toplam 1808 toprak örneği toplanmıştır. Çalışmada toprak tekstürü, doygunluk, pH, EC, \% tuz, \% kireç, $\mathrm{Ca}+\mathrm{Mg}$, Na, SAR, ESP, B, Kil Oranı I, Kil Oranı II ve Kil Oranı III içerikleri dikkate alınmıştır. Değişim katsayılarına göre doygunluk, $\mathrm{pH}, \%$ tuz, \% kireç, \% silt, \% kil, $\mathrm{Ca}+\mathrm{Mg}, \mathrm{Na}, \mathrm{SAR}$, ESP ve B özellikleri farklı eğim gruplarında önemli farklılıklar göstermiştir. Genel olarak, eğim arttıkça değişkenlik katsayısı değerleri artmış ve bu durum daha yüksek çölleşme riski olarak değerlendirilmiştir. Değişim katsayısı değerlerini dikkate alarak toprakları çölleşeme riskine bakımından gruplamanın mümkün olabileceği kanaatine varılmıştır.

Anahtar Kelimeler: Çölleşme, Değişim katsayısı, Toprak özellikleri, Aksaray.

\section{Investigation of Desertification Potential of a Land Consolidation Site with Arid and Different Slope Conditions Using Classical Statistical Methods}

\begin{abstract}
Classical statistical approaches can define the heterogeneity in soils and allow comparison of desertification tendencies of different soils. In this study, desertification tendency of a land consolidation area located in arid climate conditions with pasture and agricultural lands is evaluated by considering the coefficients of variation. In the study, coefficient of variation values were determined to define desertification tendency for sixteen soil variables at four different slopes (0-2\%, 3-6\%, 7-12\%, > 12\%). For this purpose, 1808 soil samples were collected from the Aksaray-Ortaköy district land consolidation project area. Soil texture, saturation, $\mathrm{pH}, \mathrm{EC}$, \% salt, \% lime, $\mathrm{Ca}+\mathrm{Mg}$, Na, SAR, ESP, B, Clay Ratio I, Clay Ratio II and Clay Ratio III contents were taken into consideration in the study. Saturation, pH, \% salt, \% lime, \% silt, \% clay, Ca + Mg, Na, SAR, ESP and B properties showed significant differences in different slope groups according to the coefficients of variance. Generally, the coefficient of variation values increased with increasing slope and this situation was considered as a higher risk of desertification. It has been concluded that, considering the coefficient of variation values, it is possible to group the soils in terms of desertification risk.
\end{abstract}

Keywords: Desertification, Coeficient of variation, Soil properties, Aksaray. 


\section{Giriş}

Çölleşme, kurak, yarı kurak ve yarı nemli alanlarda, iklim değişikliği veya aşırı insan faaliyetlerinden kaynaklanan arazi verimliliğinin azalması veya kaybolması sürecini ve sonuçta çöl benzeri bir ortamın oluşumunu ifade eder (Geist and Lambin, 2004). Dinamik bir süreç olan çölleşme sonucunda, topraklar sahip olduğu enerjiyi kaybederek işlevlerini yeterince yerine getiremezler. Toprak fonksiyonlarının tümü enerji üzerine dayalıdır. Bu nedenle toprak bozulmasına toprak fonksiyonlarında ya da kullanımlarındaki kayıp ya da azalma olarak bak1labilir.

Birçok araştırmacı toprakların enerji düzeylerini test ederek çölleşme potansiyellerinin araştırılabileceklerini bildirmişlerdir. Mouat et al. (1997), çölleşmeyi değerlendirmede kullanılabilecek potansiyel indikatörleri listelemiştir. Bu liste, \% organik madde, albedo, erozyon indeksi, karbon azot oranı ve tuzlulaşma gibi çeşitli toprak değişkenlerini kapsamaktadır. Miller and Donahue (1995) karbon azot oranını toprağın besleyicilik durumunu gösteren bir indikatör olarak önermiştir.

Toprak özelliklerinin mekânsal değişkenliği, jeolojik ve pedolojik toprak oluş süreçlerinin bir sonucu olarak doğasında var olmakla birlikte, değişkenliğin bir kısmı ise toprak işleme gibi çeşitli insan faaliyetlerinin bir sonucudur. Bu nedenle bir toprak özelliğinde görülen heterojenlik, çölleşmenin bir potansiyel indikatörü olabilir. Schlesinger et al. (1990), pH, \% saturasyon, toprak nem içeriği, toplam azot miktarındaki varyasyon katsayısının çölleşme indikatörü olarak kullanılabileceği ve yüksek değişim katsayısının yüksek çölleşme potansiyeline işaret ettiğini bildirmişlerdir. Klasik istatistikte, ele alınan bir toprak özelliğine ait standart sapma, değişim katsayısı ve ortalama gibi veriler yersel değişkenlikleri karakterize etmek için sıklıkla kullanıldığı bildirilmektedir (Webster, 2001).

Oğuz et al. (2011), Tokat yöresinde 1.041,2 ha alana sahip Çelikli Havzasında yaptıkları çalışmada, eğimi < $3^{\circ}$ olan hafif-orta eğimli (MMS) ve $>3^{\circ}$ fazla eğime sahip orta-dik eğimli (MSS) yerler için bazı seçilmiş toprak özelliklerinin değişim katsayısı (CV) değerlerini karşılaştırmışlardır. Çalışma bulgularına göre, genellikle ele alınan toprak özelliklerine ait CV değerleri MSS eğime sahip topraklarda, MMS topraklarına göre daha yüksek olmuştur. Araştırmacılar bu sonuca dayanarak, havzanın eğimli topraklarının daha yüksek çölleşme riski taşıdığını bildirmişlerdir.

Toprak aşınıma duyarlılık değerlerinin mekânsal değişkenliği Cezayir’ de El Hamam havzasında klasik ve modern istatistik teknikleri kullanılarak araştırılmıştır. Bu amaçla, 51 adet yüzey toprağı $(0-20 \mathrm{~cm}) 1000$ ha olan çalışma alanından alınmıştır. Havzada toprak aşınıma duyarlılık değerleri 0,16-0,66 arasında değişmiştir. Değişkenlik analizi, toprak özelliklerinin ve erozyonun işlemeli tarım alanlarında mera ve orman arazilerine göre daha fazla değiştiğini göstermiştir. Varyasyon katsayısı değerleri kil içeriği $(\% 53,04)$, orta kum içeriği $(\% 48,91)$ ve silt içeriği $(\% 27,56)$ olarak sıralanmıştır. Organik madde daha yüksek değişkenlik $(\% 63,14)$ göstermiştir. Toprak aşınabilirlik faktörü (K) değerleri \%0,36-38,82 arası değişim katsayısı değerleri göstermiştir. Değişim katsayı değerlerine göre ele alınan toprak özellikleri orta değişkenlik gösterdiği bildirilmiştir (Khanchoul and Boubehziz, 2019).

Çin'de arazi toplulaştırmasından önce ve sonra ekili arazide toprak özelliklerindeki değişkenlikleri araştırılmıştır. Bu amaçla, 2003 yılında (arazi toplulaştırmasından önce) ve 2008'de (arazi toplulaştırmasından sonra) tarım arazilerinden toprak örnekleri alınmıştır. Beş adet toprak özelliğinin ( $\mathrm{pH}$, \% organik madde, toplam $\mathrm{N}$, elverişli P ve elverişli K) dağılımı uzay-zaman korelasyonlu doğrusal bir karma model ile belirlenmiştir. Doğrusal karma model tarafından tahmin edilen toprak özelliklerinin dağılımları, arazi toplulaştırmasından sonra toprakların daha düşük bir değişkenlik gösterdiği sonucunu vermiştir. Bu durum büyük olasılıkla üst toprağın alt toprakla karışımından kaynaklandığı bildirilmiştir. Toplulaştırma sahasında yeniden parsellerin dağıtımı sonucunda, bazı bölgelerde pH yükselmiş, bazı bölgelerde ise azalmıştır. \% organik madde ve toplam N miktarı ise azalmıştır. Elverişli $\mathrm{P}$ ve $\mathrm{K}$, kimyasal gübre uygulamalarında azalışa bağlı olarak azalmıştır. Araştırmacılar, toprak verimliliğini sürdürebilmek ve toprak bozulmasını önlemek için, arazi toplulaştırmasından sonra toprak özelliklerindeki mekânsal değişikliklerin araştırılmasını önermişlerdir (Chunfa et al., 2019).

Hindistan-Himalayala'da bir kentsel alt havzada toprakların bünye (\% kum, \% silt ve \% kil), hacim ağırlığı ( $\rho$ b), gözeneklilik $(\eta)$ ve doymuş hidrolik iletkenlik (Ks) gibi bazı fiziksel özelliklerdeki değişkenlik araştırılmıştır. Bu amaçla rastgele seçilen 100 noktadan yüzey toprak örnekleri alınmıştır. Değişkenlerin toplam varyasyonu veya heterojenliği varyasyon katsayısı $(\mathrm{CV})$ ile belirlenmiştir. CV değerlerine göre, \% kum $(\mathrm{CV}=0,23)$ ve kile $(\mathrm{CV}=0,14)$ kıyasla silt bileşeninin uzaysal değişkenliğinin daha büyük $(\mathrm{CV}=0,35)$ olmuştur. Tekstürel fraksiyondaki belirlenen orta dereceli değişkenlik, çalışma alanında birden fazla toprak tekstürünün bulunmasından ve ayrıca mikrotopografik varyasyonlardan etkilenen pedojenik süreçlerden kaynaklanmış 
olabileceği bildirilmiştir. CV değerleri, $\eta$ ve Ks'nin alt havza genelinde sırasıyla 0,17 ve 0,36 oluşu ile orta derecede değişkenliğe sahip olmuştur. Hacim ağırlığı ise 0.08'lik bir CV ile en düşük değişkenliğe sahip olmuştur. Mevcut alt havzanın kentsel yerleşime maruz olması ve bu nedenle yoğun insan müdahalesine açık oluşu değişkenliğin kaynağı olarak gösterilmiştir (Rasool et al., 2020).

Çalışmada, yarı kurak iklim koşullarına sahip Aksaray-Ortaköy ilçesi arazi toplulaştırma sahası topraklarının, farklı arazi eğimi ve toprak derinliklerinde çölleşme eğilimini karşılaştırmak amaçlanmıştır. Bu amaç için, farklı eğimlerde yer alan topraklara ait bazı fiziksel ve kimyasal özellikler aritmetik ortalama, standart sapma ve değişim katsayısı gibi klasik istatistik yaklaşımlarla karşılaştırılmış ve değerlendirilmişstir.

\section{Materyal ve Metot}

\subsection{Materyal}

Bu çalışma, Aksaray İli, Ortaköy İlçesi’ne bağlı Reşadiye, Bozkır, Sarıkaraman, Devedamı, Harmandalı, Çiftevi, Gökler, Salarıalaca köyleri, Ağaçören İlçesi’ne bağlı Kütüklü, Dadılar, Camili köyleri ve Sarıyahşi İlçe merkezi ile ilçe merkezine bağlı Boğazköy ve Bekdik köylerini içeren bir arazi toplulaştırma proje sahasında yürütülmüştür. Araştırma sahası 50.673,48 ha alan kaplamakta olup Tuz Gölü Kapalı Havzası'nda yer almaktadır. Çevre uzunluğu 191.259,53 m olup, yükselti 1.118-1.430 m arasında değişmektedir. Çalışma alanının kuzeyinde Hirfanlı HES Barajı ve Kızılırmak, doğusunda Kırşehir, güneyinde Ortaköy İlçesi, batısında Sarıyahşi ve Ağaçören ilçeleri bulunmaktadır. Arazi, Kuzeybatı-Güneydoğu bakılıdır.

Çalışma yerinde, aliviyal ve kahverengi büyük toprak grupları yaygın yayılım göstermektedir. Toprak derinliği genel olarak orta derin olmasının yanında derin, sı̆̆ ve çok sı̆̆ alanlarda bulunmaktadır. Arazide düz ve düze yakın, hafif, orta eğimlerin yanında çok dik eğime de rastlanılmaktadır. Erozyon sınıfı genellikle hafif ve orta olmakla birlikte şiddetli grubuna giren alanlar da bulunmaktadır. Drenaj iyi derecede olup, fena ve yetersiz drenaj sorunu olan bölgelerde mevcuttur. Tarım yapılan alanlarda \%5-20 arasında taşlilık olup, mera ve tarım dışı arazilerde taşl11ık \%20-50 arasındadır. Topografya düz ve düze yakın, ondüleli ve dalgalı olup, genel fizyografya yüksek arazi niteliğindedir.

Araştırma alanında karasal iklim hüküm sürer. Yazları kurak ve sıcak, kışları yağışlı ve soğuk olup, kar yağışı azdır. Aksaray İli yıllık yağış ortalaması $349.1 \mathrm{~mm}$ ve yıllık toplam buharlaşma 1.341,7 mm'dir. Yıllık ortalama sicaklık $11,9^{\circ} \mathrm{C}^{\prime}$ tır (DMİ, 2017).

Aksaray-Ortaköy ilçesi arazi toplulaştırma projesi sahasında dört farklı eğimde ve derinlikten alınan toplam 1808 toprak örneği bu çalışmanın materyalini oluşturmaktadır. Araştırma yeri çoklukla tarım alanlarından oluşmakla birlikte mera alanları da yer almaktadır. Tarım alanlarında, tarla bitkileri, sebze ve meyvecilik yapılmaktadır. Tarla bitkilerinden yetiştirilen ürünler, patates, nohut, fasulye (kuru), ayçiçeği, aspir, şekerpancarı, yonca, korunga, misır ve fĭğ olup bu ürünler toplamda 71.678 da alanda üretimi yapılmaktadır. Sebzecilikte yetiştirilen ürünler, soğan, sarımsak, pırasa, havuç domates, hıyar, biber, bamya, patlıcan, kabak fasulye (yeşil), kavun, karpuz, lahana, marul, ıspanak, maydanoz ve nane olup toplamda 19.285 da alanda yetiştiriciliği yapılmaktadır. Meyvecilikte yetiştirilen ürünler, üzüm, elma, armut, erik, kayısı, kiraz, vişne, iğde, çilek, dut, badem ve ceviz olup toplamda 6.440 da alanda üretimleri yapılmaktadır. Proje sahası toplam mera alanı 67.793 da alan kaplamaktadır (Anonim, 2014).

\subsection{Metot}

\subsection{Farklı eğim gruplarının oluşturulması ve her bir grupta yer alan örnekleme noktalarının belirlenmesi}

Araştırma sahasında koordinatlı olmak üzere, $500 \mathrm{~m}$ aralıklı grid yöntemiyle daha önceden alınmış bulunan toprak örneklerine ait eğim değerlerini belirlemek üzere topoğrafik haritadan yararlanılarak arazinin sayısal yükseklik modeli (DEM) oluşturulmuştur. ArcMap yazılım yardımıyla DEM haritasından dört farklı eğim gurubu oluşturulmuştur (ESRI, 2011). Oluşturulan eğim haritası üzerinde örnekleme noktaları gösterilmek suretiyle her bir örnekleme noktası için eğim değerleri belirlenmiştir.

Çalışmada, düz veya düze yakın eğim (DE) \%0-2, hafif eğim (HE) \%3-6, orta eğim (OE) \%7-12 ve fazla eğim (FE) > \%12 olmak üzere dört farklı eğim gruplaması oluşturulmuştur. Her grup için farklı derinlikler dikkate alınarak toprak örneklerine ait çeşitli fiziksel ve kimyasal özellikleri dikkate alınmıştır. 
Dört farklı eğim grubunda yer alan toprakların bünye, suyla doygunluk, pH, EC, \% tuz, \% kireç, \% kum, \% kil, \% silt, $\mathrm{Ca}+\mathrm{Mg}, \mathrm{Na}$, SAR, ESP, B ve kil oranı I, II, III gibi toprak özellikleri çalışma alanının çölleşme eğilimini belirleyebilmek amacıyla değerlendirilmiştir. Bu amaçla, toplam 1808 adet olmak üzere, farklı noktalardan alınmış ve analiz edilmiş $0-20 \mathrm{~cm}, 20-50 \mathrm{~cm}, 50-90 \mathrm{~cm}, 90-120 \mathrm{~cm}$ derinliklere ait toprakların bazı özellikleri dikkate alınmıştır.

Çalışmada Kil Oranı I, II ve III değerleri aşağıdaki eşitlikler yardımıyla hesaplanmıştır.

Kil Oranı I = \% kum + \% silt / \% kil (Chandra, 1978)

Kil Oranı II = \% kil / \% silt + \% kum (Römkens, 1985)

Kil Oranı III $=\%$ kum $/ \%$ kil $+\%$ silt (Ngtunga et al., 1984)

\subsection{Veri analizi}

Farklı eğimlere ve derinliklere sahip toprak örneklerinin, suyla doygunluk, pH, EC, \% tuz, \% kireç, \% kum, \% kil, \% silt, Ca+Mg, Na, SAR, ESP, B ve Kil Oranı I, Kil Oranı II, Kil Oranı III gibi değerleri, değişim katsayıları dikkate alınarak değerlendirilmiştir. Farklı eğimli arazilere ait toprakların fiziksel ve kimyasal özellikleri bir çölleşme eğilimi olmak üzere, değișim katsayıları dikkate alınarak birbirleriyle karşılaştırılmıştır. Yüksek değişim katsayısı o eğim grubu içerisindeki toprakların dıș etkenlere bağlı heterojenliğine dolayısı ile çölleşme eğilimine yol açtığ1 öngörülmüştür.

\section{Bulgular ve Tartışma}

Arazi toplulaştırma sahasından dört farklı derinlik $(0-20 \mathrm{~cm}, 20-50 \mathrm{~cm}, 50-90 \mathrm{~cm}$ ve $90-120 \mathrm{~cm})$ olacak şekilde \%0-2, \%3-6, \%7-12 ve \%12< koşullarını sağlayan dört adet eğim grubunda yer alan toprakların ortalama, standart sapma ve değişim katsayı değerleri Tablo 1'de verilmiştir.

Tablo 1. Farklı eğim ve derinliklerde yer alan toprakların aritmetik ortalama, standart sapma ve değişim katsayıları.

\begin{tabular}{|c|c|c|c|c|c|c|c|c|c|c|c|c|}
\hline \multirow{3}{*}{ Toprak Özelliği } & \multicolumn{2}{|c|}{$0-20 \mathrm{~cm}$} & \multicolumn{4}{|c|}{$20-50 \mathrm{~cm}$} & \multicolumn{3}{|c|}{$50-90 \mathrm{~cm}$} & \multicolumn{3}{|c|}{$90-120 \mathrm{~cm}$} \\
\hline & AO & SS & DK & AO & SS & DK & AO & SS & DK & AO & SS & DK \\
\hline & \multicolumn{12}{|c|}{ \%0-2 Eğ gim } \\
\hline Saturasyon (\%) & 48,49 & 8,15 & 16,82 & 50,35 & 7,96 & 15,82 & 52,82 & 8,54 & 16,17 & 55,67 & 8,91 & 16 \\
\hline pH & 7,69 & 0,282 & 3,66 & 7,757 & 0,198 & 2,551 & 7,8 & 0,161 & 2,05 & 7,79 & 0,255 & 3,27 \\
\hline $\mathrm{EC}(\mu \mathrm{S} / \mathrm{cm})$ & 0,65 & 0,356 & 54,11 & 0,632 & 0,352 & 55,635 & 0,61 & 0,355 & 57,75 & 0,61 & 0,325 & 53,19 \\
\hline Tuz (\%) & 0,02 & 0,015 & 67,12 & 0,022 & 0,015 & 69,124 & 0,02 & 0,016 & 71,36 & 0,02 & 0,013 & 57,89 \\
\hline Kireç (\%) & 8,58 & 5,868 & 68,34 & 10,655 & 6,41 & 60,158 & 13,12 & 7,402 & 56,37 & 15,41 & 8,617 & 55,92 \\
\hline Kum (\%) & 53,57 & 10,704 & 19,97 & 51,581 & 10,542 & 20,438 & 49,42 & 10,924 & 22,1 & 46,54 & 12,038 & 25,86 \\
\hline Kil (\%) & 25,61 & 8,044 & 31,4 & 27,545 & 7,887 & 28,634 & 29,97 & 8,329 & 27,78 & 32,81 & 8,748 & 26,65 \\
\hline Silt (\%) & 21,34 & 5,973 & 27,98 & 21,404 & 5,909 & 27,608 & 21,14 & 6,197 & 29,3 & 21,27 & 7,272 & 34,18 \\
\hline $\mathrm{Ca}+\mathrm{Mg}$ (meq) & 4,81 & 2,771 & 57,58 & 4,456 & 2,796 & 62,753 & 4,03 & 2,408 & 59,62 & 3,74 & 2,254 & 60,12 \\
\hline $\mathrm{Na}$ (meq) & 1,73 & 2,112 & 121,86 & 1,829 & 2,115 & 115,62 & 2,1 & 2,656 & 126,1 & 2,32 & 2,37 & 102,11 \\
\hline SAR & 1,25 & 1,627 & 129,8 & 1,416 & 1,889 & 133,387 & 1,73 & 2,433 & 139,88 & 2,02 & 2,348 & 115,96 \\
\hline $\operatorname{ESP}(\%)$ & 1,4 & 1,82 & 129,81 & 1,585 & 2,114 & 133,394 & 1,94 & 2,723 & 139,92 & 2,26 & 2,628 & 115,99 \\
\hline B (ppm) & 0,07 & 0,085 & 112,18 & 0,089 & 0,104 & 116,966 & 0,09 & 0,093 & 95,95 & 0,1 & 0,071 & 68,75 \\
\hline Kil oranı I & 3,43 & 2,013 & 58,62 & 3,016 & 1,553 & 51,504 & 2,66 & 1,35 & 50,58 & 2,34 & 1,373 & 58,56 \\
\hline Kil oranı II & 0,36 & 0,155 & 43,19 & 0,397 & 0,161 & 40,65 & 0,44 & 0,187 & 41,73 & 0,51 & 0,211 & 40,92 \\
\hline \multirow[t]{2}{*}{ Kil oranı III } & 1,28 & 0,669 & 52,03 & 1,177 & 0,598 & 50,82 & 1,07 & 0,545 & 50,5 & 1,96 & 15,823 & 806,38 \\
\hline & \multicolumn{12}{|c|}{ \% 3-6 Ĕğim } \\
\hline Saturasyon (\%) & 47,06 & 7,344 & 15,6 & 49,22 & 7,524 & 15,28 & 51,89 & 9,579 & 18,46 & 53,98 & 9,344 & 17,31 \\
\hline pH & 7,62 & 0,342 & 4,48 & 7,7 & 0,276 & 3,57 & 7,73 & 0,296 & 3,83 & 7,76 & 0,324 & 4,16 \\
\hline $\mathrm{EC}(\mu \mathrm{S} / \mathrm{cm})$ & 0,6 & 0,267 & 44,44 & 0,57 & 0,251 & 43,53 & 0,56 & 0,264 & 46,71 & 0,57 & 0,336 & 58,37 \\
\hline Tuz (\%) & 0,01 & 0,01 & 54,45 & 0,01 & 0,01 & 53,4 & 0,02 & 0,012 & 60,3 & 0,02 & 0,014 & 68,59 \\
\hline Kireç (\%) & 11,14 & 8,559 & 76,82 & 12,76 & 8,853 & 69,36 & 14,02 & 9,065 & 64,64 & 14,86 & 9,256 & 62,28 \\
\hline Kum (\%) & 54,69 & 10,353 & 18,92 & 52,96 & 10,481 & 19,79 & 51,23 & 11,369 & 22,18 & 49,6 & 11,897 & 23,98 \\
\hline Kil (\%) & 24,02 & 7,24 & 30,13 & 26,07 & 7,408 & 28,41 & 28,41 & 8,707 & 30,64 & 30,48 & 9,444 & 30,98 \\
\hline Silt (\%) & 21,74 & 6,127 & 28,17 & 21,42 & 6,36 & 29,68 & 20,87 & 6,634 & 31,78 & 20,4 & 6,272 & 30,73 \\
\hline Ca+Mg (meq) & 4,82 & 2,329 & 48,28 & 4,5 & 2,162 & 48 & 4,15 & 1,797 & 43,26 & 4 & 2,477 & 61,91 \\
\hline Na (meq) & 1,17 & 1,281 & 108,64 & 1,26 & 1,292 & 102,32 & 1,46 & 1,543 & 105,65 & 1,93 & 3,057 & 158,1 \\
\hline SAR & 0,82 & 0,967 & 117,82 & 0,9 & 0,956 & 105,35 & 1,09 & 1,154 & 105,2 & 1,46 & 2,466 & 168,23 \\
\hline ESP (\%) & 0,91 & 1,082 & 117,82 & 1,01 & 1,07 & 105,31 & 1,22 & 1,291 & 105,22 & 1,64 & 2,759 & 168,2 \\
\hline B (ppm) & 0,1 & 0,159 & 157,04 & 0,11 & 0,165 & 150 & 0,11 & 0,168 & 140,4 & 0,13 & 0,177 & 131,55 \\
\hline Kil oranı I & 3,6 & 1,627 & 45,09 & 3,27 & 2,321 & 70,81 & 3,11 & 3,165 & 101,62 & 2,79 & 2,163 & 77,51 \\
\hline Kil oranı II & 0,32 & 0,138 & 42,08 & 0,36 & 0,148 & 40,37 & 0,41 & 0,198 & 47,36 & 0,47 & 0,265 & 56,31 \\
\hline Kil oranı III & 1,91 & 1,15 & 60,14 & 1,24 & 0,571 & 46,07 & 1,55 & 1,713 & 109,91 & 1,11 & 0,668 & 59,67 \\
\hline
\end{tabular}


Tablo 1. Devam ediyor.

\begin{tabular}{|c|c|c|c|c|c|c|c|c|c|c|c|c|}
\hline \multirow[t]{3}{*}{ Toprak Özelliği } & \multicolumn{3}{|c|}{$0-20 \mathrm{~cm}$} & \multicolumn{3}{|c|}{$20-50 \mathrm{~cm}$} & \multicolumn{3}{|c|}{$50-90 \mathrm{~cm}$} & \multicolumn{3}{|c|}{$90-120 \mathrm{~cm}$} \\
\hline & AO & SS & DK & AO & SS & DK & AO & SS & DK & AO & SS & DK \\
\hline & \multicolumn{12}{|c|}{ \%7-12 Ĕ̆im } \\
\hline Saturasyon (\%) & 45,63 & 7,868 & 17,24 & 47,72 & 8,122 & 17,01 & 49,69 & 7,819 & 15,73 & 50,5 & 9,147 & 18,11 \\
\hline pH & 7,57 & 0,365 & 4,82 & 7,69 & 0,262 & 3,4 & 7,7 & 0,285 & 3,69 & 7,66 & 0,428 & 5,59 \\
\hline EC $(\mu \mathrm{S} / \mathrm{cm})$ & 0,59 & 0,296 & 49,84 & 0,58 & 0,324 & 55,78 & 0,57 & 0,342 & 59,85 & 0,55 & 0,347 & 62,15 \\
\hline Tuz (\%) & 0,01 & 0,011 & 56,15 & 0,01 & 0,012 & 60,41 & 0,02 & 0,012 & 61,22 & 0,02 & 0,012 & 59,89 \\
\hline Kireç (\%) & 10,62 & 9,202 & 86,62 & 12,35 & 9,41 & 76,19 & 14,19 & 10,096 & 71,11 & 14,74 & 10,632 & 72,11 \\
\hline Kum (\%) & 56,54 & 12,025 & 21,26 & 54,55 & 12,468 & 22,85 & 53,61 & 12,336 & 23 & 53,66 & 13,848 & 25,8 \\
\hline Kil (\%) & 22,41 & 7,777 & 34,69 & 24,75 & 8,022 & 32,4 & 26,5 & 8,055 & 30,38 & 26,96 & 9,726 & 36,07 \\
\hline Silt (\%) & 21,46 & 7,098 & 33,07 & 21,1 & 6,827 & 32,34 & 20,36 & 7,066 & 34,69 & 19,83 & 6,819 & 34,37 \\
\hline $\mathrm{Ca}+\mathrm{Mg}$ (meq) & 4,92 & 2,879 & 58,5 & 4,65 & 2,982 & 64,04 & 4,37 & 2,873 & 65,71 & 4,06 & 3,264 & 80,35 \\
\hline $\mathrm{Na}(\mathrm{meq})$ & 1,02 & 0,648 & 63,55 & 1,09 & 0,659 & 60,34 & 1,23 & 0,802 & 65,04 & 1,51 & 1,194 & 78,82 \\
\hline SAR & 0,72 & 0,594 & 81,8 & 0,81 & 0,654 & 80,52 & 0,92 & 0,635 & 68,32 & 1,24 & 1,107 & 89,19 \\
\hline ESP (\%) & 0,81 & 0,664 & 81,78 & 0,9 & 0,731 & 80,54 & 1,03 & 0,711 & 68,39 & 1,38 & 1,239 & 89,19 \\
\hline B (ppm) & 0,09 & 0,158 & 161,47 & 0,09 & 0,158 & 161,02 & 0,11 & 0,154 & 135,56 & 0,11 & 0,097 & 81,31 \\
\hline Kil oranı I & 4,19 & 2,411 & 57,51 & 3,63 & 2,094 & 57,6 & 3,27 & 1,781 & 54,42 & 3,73 & 4,139 & 110,9 \\
\hline Kil oranı II & 0,3 & 0,141 & 46,46 & 0,34 & 0,153 & 44,39 & 0,37 & 0,157 & 41,73 & 0,39 & 0,198 & 50,01 \\
\hline \multirow[t]{2}{*}{ Kil oranı III } & 1,51 & 0,869 & 57,32 & 1,4 & 0,833 & 59,15 & 1,34 & 0,775 & 57,74 & 2,15 & 3,64 & 169,07 \\
\hline & \multicolumn{12}{|c|}{$\% 12$ Eğim } \\
\hline Saturasyon (\%) & 43,63 & 7,536 & 17,27 & 46,31 & 7,972 & 17,21 & 48,49 & 8,796 & 18,13 & & & \\
\hline pH & 7,5 & 0,401 & 5,34 & 7,65 & 0,335 & 4,37 & 7,66 & 0,295 & 3,85 & & & \\
\hline EC $(\mu \mathrm{S} / \mathrm{cm})$ & 0,55 & 0,263 & 47,6 & 0,54 & 0,293 & 53,37 & 0,48 & 0,21 & 43,6 & & & \\
\hline Tuz (\%) & 0,01 & 0,009 & 52,12 & 0,01 & 0,009 & 52,54 & 0,01 & 0,01 & 57,47 & & & \\
\hline Kireç (\%) & 9,68 & 9,739 & 100,55 & 12,3 & 10,737 & 87,24 & 11,64 & 9,753 & 83,72 & & & \\
\hline Kum (\%) & 58,68 & 11,941 & 20,34 & 55,61 & 12,977 & 23,33 & 55,28 & 15,12 & 27,34 & & & \\
\hline Kil (\%) & 20,57 & 7,583 & 36,85 & 23,25 & 8,068 & 34,69 & 25,47 & 8,942 & 35,1 & & & \\
\hline Silt (\%) & 21,22 & 8,75 & 41,22 & 21,56 & 10,091 & 46,79 & 19,81 & 7,474 & 37,73 & & & \\
\hline $\mathrm{Ca}+\mathrm{Mg}$ (meq) & 4,64 & 2,627 & 56,6 & 4,46 & 2,949 & 66,02 & 3,66 & 2,155 & 58,81 & & & \\
\hline $\mathrm{Na}$ (meq) & 0,87 & 0,527 & 60,14 & 1,01 & 0,57 & 56,17 & 1,15 & 0,815 & 70,45 & & & \\
\hline SAR & 0,65 & 0,667 & 101,67 & 0,82 & 0,905 & 110,15 & 1,21 & 1,972 & 162,84 & & & \\
\hline ESP (\%) & 0,73 & 0,747 & 101,79 & 0,91 & 1,011 & 110,07 & 1,35 & 2,206 & 162,65 & & & \\
\hline B (ppm) & 0,08 & 0,11 & 130,79 & 0,13 & 0,22 & 169,02 & 0,09 & 0,059 & 62,65 & & & \\
\hline Kil oranı I & 4,92 & 3,574 & 72,62 & 4,35 & 4,028 & 92,48 & 3,68 & 2,462 & 66,88 & & & \\
\hline Kil oranı II & 0,26 & 0,126 & 46,7 & 0,31 & 0,142 & 44,97 & 0,35 & 0,166 & 46,45 & & & \\
\hline Kil oranı III & 1,63 & 0,812 & 49,58 & 1,49 & 0,912 & 61,17 & 1,61 & 1,314 & 81,43 & & & \\
\hline
\end{tabular}

AO: aritmetik ortalama, SS: standart sapma, DK: değişim katsayısı.

Toprak özelliklerinin değişkenliği değişim katsayısı değerleri dikkate alınarak üç grupta incelenmiştir. Yüzde değişim katsayısı 15' ten küçük olanlar düşük derecede değişken, 16 ile 35 arası olanlar orta derecede değişken ve 36'dan büyük olanlar yüksek derecede değişken olarak sınıflandırılmıştır (Upchurch et al., 1988). Bu değerlendirme kriterlerine göre araştırma yeri düz eğimli, 0-20 cm derinliğe sahip üst toprakları için pH düşük, saturasyon, EC, \% kum, \% kil, \% silt orta derecede ve \% tuz, \% kireç, Ca+Mg, Na, SAR, ESP, B, kil oranı I, II ve III yüksek derecede değişkenlik göstermiştir. 20-50 cm toprak derinlikleri toprak özelliklerinden pH, suyla doygunluk düşük derecede değişken, \% kum, \% kil, \% silt orta derecede değişken ve EC, \% tuz, \% kireç, Ca+Mg, $\mathrm{Na}$, SAR, ESP, B, kil oranı I, II ve III yüksek derecede değişkenlik göstermiştir. 50-90 cm derinlik toprak özelliklerinden pH düşük derecede değişkenlik, suyla doygunluk, \% kum, \% kil, \% silt orta derecede değişkenlik ve EC, \% tuz, \% kireç, $\mathrm{Ca}+\mathrm{Mg}, \mathrm{Na}, \mathrm{SAR}, \mathrm{ESP}, \mathrm{B}$, kil oranı I, II ve III yüksek derecede değişkenlik göstermiştir. 90-120 cm derinlik toprak özellikleri ise $\mathrm{pH}$, suyla doygunluk, \% kum, \% kil, \% silt orta derecede değişkenlik ve EC, \% tuz, \% kireç, Ca+Mg, Na, SAR, ESP, B, kil oranı I, II ve III yüksek derecede değişkenlik göstermiştir (Tablo 1).

Hafif eğimli ve 0-20 cm derinliğe sahip toprak özelliklerinden $\mathrm{pH}$, suyla doygunluk, \% kum, \% kil, \% silt orta derecede değişkenlik ve EC, \% tuz, \% kireç, Ca+Mg, Na, SAR, ESP, B, kil oranı I, II ve III yüksek derecede değişkenlik göstermiştir. 20-50cm derinlik için toprak özelliklerinden sadece pH düşük derecede değişkenlik gösterirken, suyla doygunluk, \% kum, \% kil ve \% silt orta derecede değişkenlik göstermiş, EC, \% tuz, \% kireç, $\mathrm{Ca}+\mathrm{Mg}, \mathrm{Na}, \mathrm{SAR}$, ESP, B, kil oranı I, kil oranı II ve kil oranı III yüksek derecede değişkenlik göstermiştir. 5090cm derinlikte toprak özelliklerinden sadece pH düşük derecede değişkenlik gösterirken, suyla doygunluk, \% kum, \% kil ve \% silt orta derecede değişkenlik göstermiş, EC, \% tuz, \% kireç, Ca+Mg, Na, SAR, ESP, B, kil oranı I, kil oranı II ve kil oranı III yüksek derecede değişkenlik göstermiştir. $90-120 \mathrm{~cm}$ derinlikte toprak özelliklerinden sadece $\mathrm{pH}$ düşük derecede değişkenlik gösterirken, suyla doygunluk, \% kum, \% kil ve \% silt orta derecede değişkenlik göstermiş, EC, \% tuz, \% kireç, $\mathrm{Ca}+\mathrm{Mg}, \mathrm{Na}, \mathrm{SAR}, \mathrm{ESP}, \mathrm{B}$, kil oranı I, kil oranı II ve kil oranı III yüksek derecede değişkenlik göstermiştir (Tablo 1).

Orta eğim grubu topraklarda 0-20 cm derinlikte toprak özelliklerinden sadece pH düşük derecede değişkenlik gösterirken, suyla doygunluk, \% kum, \% kil ve \% silt orta derecede değişkenlik göstermiş, EC, \% tuz, \% kireç, $\mathrm{Ca}+\mathrm{Mg}, \mathrm{Na}, \mathrm{SAR}, \mathrm{ESP}, \mathrm{B}$, kil oranı I, kil oranı II ve kil oranı III yüksek derecede değişkenlik göstermiştir. 020cm derinlikte toprak özelliklerinden sadece $\mathrm{pH}$ düşük derecede değişkenlik gösterirken, \% kum, \% kil ve \% silt orta derecede değişkenlik göstermiş, EC, \% tuz, \% kireç, $\mathrm{Ca}+\mathrm{Mg}, \mathrm{Na}, \mathrm{SAR}, \mathrm{ESP}, \mathrm{B}$, kil oranı I, kil oranı II 
ve kil oranı III yüksek derecede değişkenlik göstermiştir. 50-90cm derinlikte toprak özelliklerinden sadece $\mathrm{pH}$ düşük derecede değişkenlik gösterirken, \% kum, \% kil ve \% silt orta derecede değişkenlik göstermiş, EC, \% tuz, $\%$ kireç, $\mathrm{Ca}+\mathrm{Mg}, \mathrm{Na}$, SAR, ESP, B, kil oranı I, kil oranı II ve kil oranı III yüksek derecede değişkenlik göstermiştir. 90-120cm derinlikte toprak özelliklerinden sadece $\mathrm{pH}$ düşük derecede değişkenlik gösterirken, suyla doygunluğu, \% kum ve \% silt orta derecede değiş̧enlik göstermiş, EC, \% tuz, \% kireç, \% kil, Ca+Mg, Na, SAR, ESP, B, kil oranı I, kil oranı II ve kil oranı III yüksek derecede değişkenlik göstermiştir (Tablo 1).

Yüksek eğim grubu topraklarda $0-20 \mathrm{~cm}$ derinlikte toprak özelliklerinden sadece $\mathrm{pH}$ düşük derecede değişkenlik gösterirken, suyla doygunluk ve \% kum orta derecede değişkenlik göstermiş, EC, \% tuz, \% kireç, \% kil, \% silt, $\mathrm{Ca}+\mathrm{Mg}, \mathrm{Na}$, SAR, ESP, B, kil oranı I, kil oranı II ve kil oranı III yüksek derecede değişkenlik göstermiştir. 20$50 \mathrm{~cm}$ derinliğe sahip toprak özelliklerinden sadece $\mathrm{pH}$ düşük derecede değişkenlik gösterirken, suyla doygunluk, \% kum ve \% kil orta derecede değişkenlik göstermiş, EC, \% tuz, \% kireç, \% silt, Ca+Mg, Na, SAR, ESP, B, kil oranı I, kil oranı II ve kil oranı III yüksek derecede değişkenlik göstermiştir. 50-90 cm derinliğe sahip toprak özelliklerinden sadece $\mathrm{pH}$ düşük derecede değişkenlik göstermiştir. Suyla doygunluk, \% kil ve \% kum orta derecede değişkenlik göstermiş, EC, \% tuz, \% kireç, \% silt, Ca+Mg, Na, SAR, ESP, B, kil oranı I, kil oranı II ve kil oranı III yüksek derecede değişkenlik göstermiştir (Tablo 1).

Genel olarak, bölgesel düzeyde pH' nın birbirlerine oldukça yakın değerler göstermesi beklenen bir durumdur. Suyla doygunluk ve tekstürel değişimlerin genellikle orta düzeyde olması, araştırmaya konu toplulaştırma bölgesinde taşkın veya erozyonla kısmi toprak hareketlerinin olduğu veya toprak oluş süreçlerinin etkilerinin bir sonucu olabilir. Araştırma yerinde yüksek değişkenlik gösteren toprak özellikleri yıkanma ve yüzey akış ile bağlantılı olabilir. Özellikle EC, tuz ve kireç taşınımı ve yüzeyde akümüle olması yağış, yüzey akış ve buharlaşmada görülen ortak etkileşimin bir sonucu olarak değerlendirilmiştir.

Kil oranlarının, yüksek varyasyon göstermesi, araştırma yeri topraklarının erozyona karşı tepkilerinin oldukça değişken olduğuna işaret etmektedir. Yürütülen bir araştırma sonucuna göre aşınıma duyarlılık ile kil oranı I değerleri arasında pozitif, kil oranı II vekil oranı III değeri arasında negatif bir ilişki belirlenmiştir (Oğuz ve Durak, 1998). Artan kil oranı I değeri toprakların aşınıma duyarlılığını artırırken, kil oranı II ve kil oranı III değerleri arttıkça toprakların aşınıma duyarlılığı azalmaktadır. Toprak aşınıma duyarlılık indeksi olarak kullanılan kil oranlarındaki yüksek varyasyon farklı eğimlerin toprak kayıplarına vermiş oldukları farklı cevapların bir sonucu olarak değerlendirilmiştir.

Çözünebilir Ca ve $\mathrm{Mg}$ bileşikleri yıkanma koşullarında toprak profilinden yıkanarak uzaklaşırken kurak ve yarı kurak bölgelerde yeterli yıkanma koşulları oluşamadığından toprak profilinde birikme suretiyle toprakların bazla doygunluğunu yükseltmektedir. $\mathrm{Ca}+\mathrm{Mg}$ değerinde gözlemlenen yüksek değişkenlik yağış, yüzey akış ve buharlaşma ile toprak profilindeki nem dağılımında görülen dinamik yapının bir sonucu olarak değerlendirilmektedir. Toprak profilinde farklı düzeylerde ve derinliklerde oluşan nem hareketlerine bağlı olarak yüksek varyasyon oluşmuştur. Aşırı alkalin toprakların sodyum durumunu karşılaştırmak amacıyla kullanılan $\mathrm{Na}$, SAR ve ESP değerleri yüksek değişkenlik göstermekle birlikte üst topraklar için bitkisel üretimi sınırlayacak değerlerde olmamıştır.

Dört farklı eğim grubu için çeşitli toprak özelliklerinin değişim katsayı değerleri arasındaki farklılığın önem durumu $t$ testi ile karşılaştırılmıştır. Bir toprak özelliğine ait değişim katsayısı değerleri her eğim grubuna ait toprak derinlikleri dikkate alınarak diğer eğim gruplarıyla karşılaştııılmıştır. Yapılan $t$ istatistiği sonucu elde edilen veriler Tablo 2'de verilmiştir.

Tablo 2. Toprak özelliklerine ait değişim katsayısı değerleri ile eğim grupları arasındaki istatistiksel ilişki.

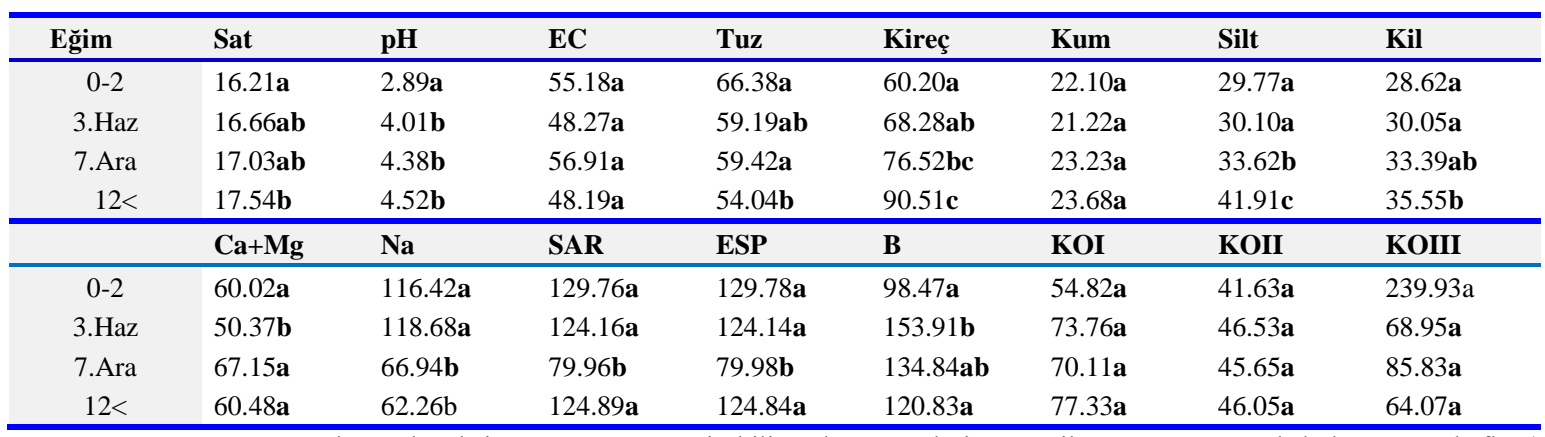

Sat.: Satürasyon, \%, SAR: Sodyum absorbsion oranı, ESP: Değişebilir sodyum yüzdesi, KO: Kil oranı, aynı sütunda bulunan aynı haflar (a, b) istatistiksel olarak önemli farklılık olmadığını göstermektedir. 
$\mathrm{Bu}$ değerlendirmeye göre, toprakların EC, \% kum, kil oranı I, kil oranı II ve kil oranı III değerlerinin değişim katsayıları farklı eğimlerde anlamlı farklılıklar göstermemiştir. Ancak ele alınan diğer toprak özelliklerine (saturasyon, pH, tuz, kireç, silt, kil, $\mathrm{Ca}+\mathrm{Mg}, \mathrm{Na}, \mathrm{SAR}$, ESP ve B) ait değişim katsayıları farklı eğim gruplarında istatistiksel olarak önemli farklılıklar göstermiştir.

Farklı eğimlere sahip toprakların saturasyon değerlerinin değişim katsayı değerleri \%0-2 ile \%12< eğimlerde anlamlı farklılık göstermiştir. \%12< eğimlerde saturasyon değişim katsayısının düz eğim grubuna göre göstermiş olduğu daha yüksek değer $t$ istatistiğine göre önemli olmakla birlikte aslında diğer eğim gruplarının değişim katsayı değerlerine oldukça yakındır. Bu nedenle saturasyon değerlerine ilişkin değişim katsayısı değeri üzerinden iyi bir çölleşme indikatörü olarak ele alınmaması daha uygun bulunmuştur.

pH değerlerinin farklı eğim gruplarının değişim katsayı değerleri \%0-2 eğim grubu ve geri kalan eğim grupları için t istatistiğine göre anlamlı farklılık göstermiştir. \%0-2 eğim grubunda yer alan toprakların pH değerleri değişim katsayıları ortalama 2,89 olur iken diğer eğim grubu topraklarında değişim katsayıları 4,01-4,52 arasında değişmiştir. Yöre toprakların $\mathrm{pH}$ değerlerindeki varyasyon farklı eğim gruplarının heterojenliğini tanımlamada uygun bir indikatör olabileceği değerlendirilmiştir.

Toprakların tuz içeriğine ilişkin değişim katsayı değerleri farklı eğim grupları için anlamlı değişiklikler göstermiştir. \%0-2 eğim grubu değişim katsayısı değerleri diğer eğim gruplarına göre daha yüksek olmuştur. Özellikle tarımsal potansiyelin daha fazla olduğu bu eğim grubunda gübreleme ve sulama gibi kültürel uygulamalarda oluşan farklılıklar değişim katsayısı değerlerinin daha yüksek olmasına yol açmıştır. Özellikle yöre topraklarının kimyasal bozulma risklerini tanımlamak için toprakların tuz içeriğinin yüksek değişim katsayısı göstermesi bir çölleşme indikatörü olarak önerilebilir.

Bu araştırma bulgularına göre artan eğime bağlı olarak toprakların kireç içerikleri değişim katsayıları da artmıştır. İstatistiksel olarak değişim katsayılarında görülen varyasyon önemlidir. Özellikle \% 7 eğim üzeri topraklarda kireç içeriklerinin değişim katsayısı oldukça artmaktadır. Yöre topraklarının fiziksel bozulma süreçlerini tanımlamada kireç içeriklerinin değişim katsayı değerlerinin karşılaştırılması uygun bir indikatör olarak görülmektedir.

Toprak bünyesi bir yörenin çölleşme eğilimini belirlemede önemli bir indikatör olarak görülmektedir. Araştırma yöresinde ise toprakların kum içeriklerine ait değişim katsayıları arasındaki farklılık önemli bulunmamıştır. Bu durumda yöre için toprakların kum içeriklerinin değişim katsayılarının bir çölleşme indikatörü olarak dikkate alınmasının uygun olmayacağı söylenebilir. Bununla birlikte toprakların silt içerikleri değişim katsayıları eğime bağlı olarak anlamlı farklılık göstermiştir. Genel olarak artan eğim silt içeriklerinin değişim katsayılarında da artışa neden olmuştur. Toprakların kum içeriğine göre daha küçük zerre iriliğine sahip olması silt taşınımı veya birikme olaylarının özellikle \%7 < eğimlerde toprak fraksiyonları içerisinde yüksek değişkenlik göstermesine yol açtığı düşünülmektedir. Bu nedenle yöre topraklarının silt içeriklerine ait değişim katsayılarının karşılaştırılması ile fiziksel bozulmayı tanımlamada bir çölleşme göstergesi olarak kullanılabileceği kanaatine varılmıştır. Toprakların en ince fraksiyonu olan kil kapsamlarının ortalama değişim katsayısı eğim gruplarına göre anlamlı farklı1ık göstermiştir. Silt içeriğinde olduğu gibi \% > eğim grupları için artan değişim katsayısı değerleri fiziksel bozulma ve erozyon süreçlerini tanımlamada değerli bir indikatör olduğu kanaatine varılmıştır.

Yöre toprakları bazik karakterde olup, $\mathrm{Ca}+\mathrm{Mg}$ kapsamları yüksektir. $\mathrm{Ca}+\mathrm{Mg}$ kapsamlarının değişim katsayıları farklı eğim grupları için t istatistiği ile olası farklılıkların önem durumu karşılaştırılmıştır. Yapılan istatistiksel değerlendirmeye göre $\mathrm{Ca}+\mathrm{Mg}$ kapsamlarının değişim katsayısı değerleri arasındaki en fazla varyasyon \%0-2, \%712 ve \%12 < eğim gruplarında olup \%3-6 eğim grubu daha düşük değişim katsayısı değerleriyle diğer eğim gruplarından ayrılmıştır. $\mathrm{Ca}+\mathrm{Mg}$ kapsamları ana materyalle ilişkili oluşu ve toprak nem dinamiğiyle hareket halinde oluşu, yöre topraklarının bazla doygunluğunun bir çölleşme eğilimi olarak değerlendirilmesini zorlaştırmıştır. Bu nedenle bu araştırma bulgularına göre çölleşme eğilimi amacıyla yöre topraklarının $\mathrm{Ca}+\mathrm{Mg}$ kapsamlarına ilişkin değişim katsayısı değerinin kullanılması önerilmemektedir.

Toprakların Na, SAR ve ESP değerlerinin değişim katsayıları farklı eğimler için anlamlı farklılıklar göstermiştir. Toprakların Na içeriği değişim katsayısı değerleri özellikle \%0-6 eğim gruplarında oldukça yüksek olmuştur. Bu nedenle toprakların kimyasal bozulmalarını tanımlamak amacıyla kullanılabilir bir yaklaşım olarak görülmüştür. Ancak SAR ve ESP değerlerinin değişim katsayıları farklı eğim gruplarında farklı olmuştur. Bu değerler özellikle \%7-12 eğim grubunda anlamlı azalış göstermiştir. Bu nedenle kimyasal bozulmayı tanımlamak amacıyla yapılacak çalışmalarda değişim katsayısı değerleri kullanılarak bir karşılaştırma yapılması halinde toprakların Na içeriklerinin değişim katsayısının dikkate alınması daha yararlı olacaktır.

Toprak B kapsamlarına ilişkin değişim katsayıları düz eğimlerde daha düşük bir durum göstermiş, artan eğimle 
değişim katsayısı değeri de artmıştır. Ancak \%12 < eğim grubunda tekrar azalarak düz eğim grubu toprakların B içerikleri değişim katsayıları ile istatistiksel olarak aynı gruba girmiştir. Ana materyal etkisi ve sulamayla yıkanmanın aktif etkisi nedeniyle yöre topraklarının çölleşme eğiliminin karşılaştırılmasında tatminkâr sonuç vermeyeceği düşünülmektedir.

\section{Sonuç ve Öneriler}

Çalışma alanı için çölleşme riskini değerlendirmek amacıyla değişim katsayısı farklı eğim grupları için dikkate alındığında, EC, \% kum ve kil oranı değerleri (K.O I, K.O II ve K.O III)’ nin eğim gruplarındaki değişimi yeterince yansıtmadığı görülmüştür. Bu nedenle çalışma bölgesi için çölleşme eğilimini belirlemek amacı ile değişim katsayı değerleri ile eğim grupları arasında önemli farklılıklar gösteren, saturasyon, pH, \% tuz, \% kireç, \% silt, \% kil, Ca+Mg, Na, SAR, ESP ve B değerleri çölleşme eğilimini tanımlamada değerlendirilebilir bulunmuştur.

Çalışma yeri topraklarının değişim katsayısı değerleri genel olarak düz eğimler ile diğer eğimler arasında farklılıklar göstermiştir. Bu farklılık düz ve çok dik eğimlerde çok belirgindir. Değişkenlikler hafif ve orta eğim gruplarında daha az olmuştur.

Ele alınan birçok toprak özelliğine ait değişim katsayısı değerleri, artan eğimle birlikte artmıştır. Bu heterojenlik eğilimi, tuz gibi suya bağlı olarak hareket kabiliyeti yüksek olan toprak özelliklerinde düz tarım arazileri için daha yüksek değişkenlik oluşmasına etki etmiştir.

Yaptığımız bu çalışmada değişim katsayısı ele alınan toprak özelliğindeki riski tanımlamada oldukça tatminkar sonuçlar vermiştir. Değişimlerde \%12 yi aşan eğimler bir kırılma noktası göstermiştir.

Bu çalışmada ele alınmayan çölleşme indikatörü olabilecek diğer toprak özelliklerinin de ileriki çalışmalarda ele alınması önerilir. Düz arazilerde daha çok toprak kimyasal özellikleri heterojenlik kaynağı olduğu düşünülmektedir. Fiziksel özelliklerden \% silt içeriğindeki değişiklik, ana materyalden kaynaklı olabileceği gibi çölleşme indikatörü olarak da kullanılabileceği düşünülmektedir.

\section{Kaynaklar}

1. Anonim (2014). Aksaray İli Ortaköy İlçesi AT ve TİGH Projesi Planlama Toprak Etüt ve Toprak Endeksi Raporu

2. Chandra, S. (1978). A Simple laboratory aparatus to measure relative erodibility of soils. Soil Science 25:115-119.

3. Chunfa, W., Jingyi, H., Hao, Z., Limin, Z., Budiman, M., Ben, P.M., Alex, B.M.B. (2019). Spatial changes in soil chemical properties in an agricultural zone in southeastern China due to land consolidation. Soil and Tillage Research, 187, 152-160.

4. DMI (2017). Aksaray İli uzun yıllık meteorolojik verileri (Yazılı Görüşme).

5. ESRI (2011). Environmental Systems Research Institute, ArcGIS for Desktop, Version 10.1. - Redlands CD ROM.

6. Geist, H.J., Lambin, E.F. (2004). Dynamic causal patterns of desertification, Bioscience, 54:9, pp. 817829.

7. Khanchoul, K., Boubehziz, S. (2019). Spatial variability of soil erodibility at El Hammam Catchment, Northeast of Algeria, Environment \& Ecosystem Science, 3:1, 17-25.

8. Miller, R.W., Donahue, R.L. (1995). Soils in Our Environment. 7th edition, Prentice Hall, New Jersey, USA.

9. Mouat, D., Lanchester, J., Wade, T., Wickham, J., Fox, C., Kepner, W., Ball, T. (1997). Desertification evaluated using an integrated environmental assessment model. Environ. Monitoring \& Assessment, 48, 139-156.

10. Ngatunga, E.L.N., Lal, R., Uriyo, A.P. (1984). Effects of surface management on runoff and soil erosion from some plots at Mlingano, Tanzania. Geoderma, 33:1, 1-12.

11. Ŏguz, İ., Durak, A. (1998). Çekerek Havzası Büyük Toprak Gruplarının Bazı Özellikleri ile Su Erozyonu İlişkileri ve Havza Topraklarının Erozyona Duyarlılık Değerlendirmesi. Toprak ve Su Kaynakları Araştırma Sonuç Raporları, Ankara.

12. Oğuz,I., Erşahin, S., Susam, T. (2011). Evaluation of desertification potential in a sloping catchment. Carpathian Journal of Earth and Environmental Sciences, 6:1, p.81-88. 
13. Rasool, T., Dara, A.Q., Wani, M.A. (2020). Quantification of spatial variability of soil physical properties in a Lesser Himalayan Sub-Basin of India. Eurasian Soil Science, 53:3, 362-376.

14. Römkens, M.J.M. (1985). The Soil Erodibility Factor: A Perspective. Soil Conservation Society of American, p 445-460, USA.

15. Schlesinger, W.H., Reynolds, J.F., Gunningham, G.L., Huenneke, L.F., Jarrel, W.M., Wirginia, R.A., Whitford, W.G. (1990). Biological feedbacks in global desertification. Science, 247, 1043-1048.

16. Upchurch, D.R., McMichael B.L., Taylor, H.M. (1988). Use of minirhizotrons to characterize root system orientation. Soil Science Society of America Journal, 52: 2, 319-323.

17. Webster, R. (2001). Statistics to support soil research and their presentation. European Journal of Soil Sciences, 52, 331-340. 